\section{Reform at WHO is too slow, say critics}

Phyllida Brown, London

The World Health Assembly starts next week (17 May 1999), but nine months after Gro Harlem Brundtland took the helm at the World Health Organisation, two key directors' posts remain unfilled, and some frustrated insiders claim that her hectic reform programme is not fast or radical enough to meet the challenges the WHO faces.

Dr Brundtland took office last July with a promise that the beleaguered UN agency would change and "make a difference" to global health. Most former critics of the WHO have praised her achievements so far. The headquarters has been restructured to improve communication and effectiveness, and the number of programme directors has been cut from more than 50 to 36 .

Yet some within the agency say privately that there is less new blood than they hoped, and that lack of money, legal obstacles, and bureaucratic inertia have hampered change. "Brundtland is doing the best she can, but it is going to take

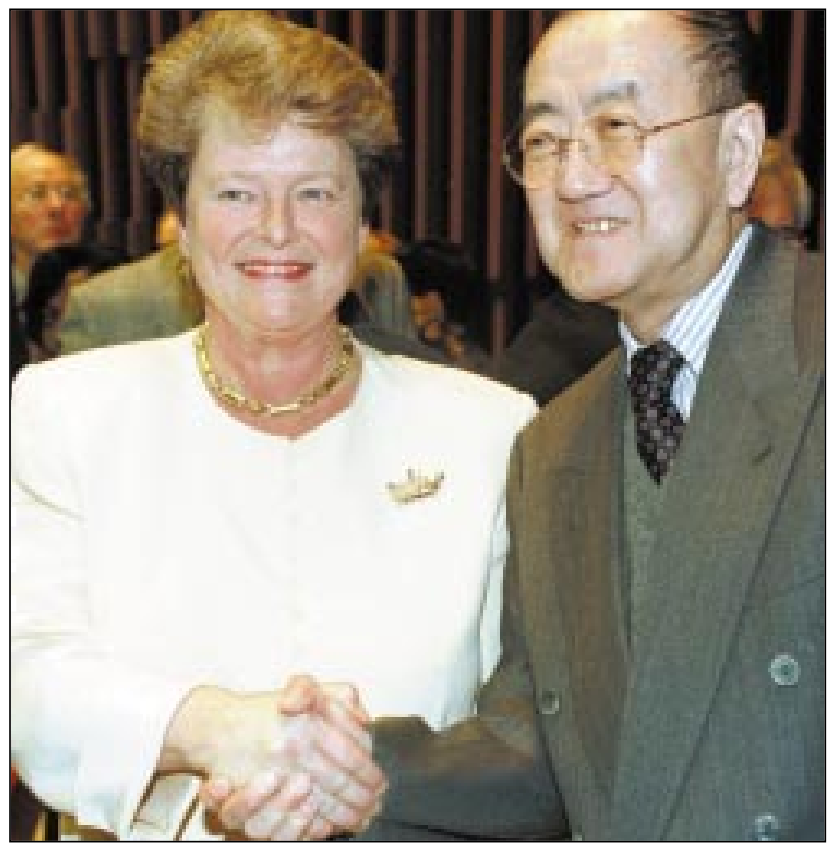

Critics say that Gro Harlem Brundtland, shown with former WHO chief Hiroshi Nakajima, hasn't delivered promised changes

three or four years," said one senior staff member.

One key component of $\mathrm{Dr}$ Brundtland's vision is to make the WHO an authoritative source of data for health policymakers. She has set up a new "cluster" of activities, called Evidence and Information for Policy, to implement this vision. Yet the post of a programme director to coordinate research within the cluster remains vacant. Meanwhile, decisions on new collaborating centres, research institutions with which the WHO has formal links, have been suspended.

"Many of our research colleagues are asking what's going on," admitted one insider. The post of director for women's health and development also remains unfilled. And the organisation has not begun to advertise and interview for its dozens of team coordinators, the next level down from programme directors. Some within the agency say that there is also still a sex imbalance at headquarters.

WHO officials say that these criticisms are unjustified. A spokesman said that of three dozen programme directors, 30 were "new"-although an unstated number of them were in fact promoted from within the organisation. Fourteen of the newly appointed directors are women.

Despite the criticisms, Dr Brundtland's staff believe that they have made significant progress on her "fast tracked" topics, including malaria and tobacco control. At the World Health Assembly member states are expected to approve the use of the agency's treaty making powers to give teeth to the Framework Convention on Tobacco Control, making it the world's first "public health treaty."

"If they agree, this will be the first time [these powers] have been used in the agency's history," says Derek Yach of the WHO's Tobacco Free Initiative. $\square$

\section{Some HIV patients can stop taking prophylaxis against infections}

Scott Gottlieb, New York

Patients infected with HIV whose immune systems have responded well to combination antiretroviral treatment can stop taking prophylaxis for Pneumocystis carinii pneumonia, a study in the New England Journal of Medicine has found (1999;340:1301-6).

The study, conducted by $\mathrm{Dr}$ Hansjakob Furrer and colleagues from the Bern Hospital in Switzerland, followed 262 patients who had stopped taking the prophylaxis. While the patients were on triple therapy, their $\mathrm{CD} 4$ counts rebounded to at least $200 \times 10^{6}$ cells $/ 1$ for three months or longer.

Two patients died during the 11 months of follow up, and nine had to start taking prophylaxis again because they were not responding to antiretroviral treatment. But none of the remaining patients who had stopped the antibiotic prophylaxis contracted Pneumocystis carini pneumonia during follow up.

Ten years ago, the United States Public Health Service recommended that patients with low blood counts resulting from HIV take a lifelong regimen of trimethoprim-sulfamethoxazole to protect themselves from contracting pneumonia. Until now it was unclear whether primary prophylaxis for Pneumocystis carinii pneumonia could be discontinued by patients with HIV who had successfully been treated with combination antiretroviral treatment.

The study confirms that antiretroviral regimens containing protease inhibitors have the ability to restore immune function enough to obviate the need for lifelong prophylaxis against some opportunistic infections.

In an accompanying editorial, Dr Henry Masur of the National Institutes of Health and Dr Jonathan Kaplan of the Centers for Disease Control and Prevention, noted that although the antibiotic prophylaxis against Pneumocystis carinii pneumonia is inexpensive, withdrawing treatment could help simplify the complicated drug regimens that many patients currently use (New England Journal of Medicine 1999;340:1356-7).

"The discontinuation of an inexpensive drug that is taken once daily may seem trivial given the complexity of most HIV regimens, but such a step would not only simplify the regimen but also provide a psychological benefit, by affirming that immunologic function is improved."

\section{Thousands of smear tests reviewed}

\section{Doug Payne, Dublin}

Thousands of cervical smear tests from seven hospitals in the Republic of Ireland are being reviewed after the discovery of anomalies in results from a private laboratory in 1997. Screening carried out by Claymon Laboratories, in Dublin, for private clients, including GPs, is also to be investigated.

Concerns were raised after an audit by the North Western Health Board showed that the rate of abnormal smears returned by Claymon was lower than expected. Tests were rechecked by a laboratory in Glasgow, and 68 women were reported as having been misdiagnosed. 